\title{
Basic considerations in the dermatokinetics of topical formulations
}

\author{
Anroop Nair ${ }^{1, *}$, Shery Jacob ${ }^{2}$, Bandar Al-Dhubiab ${ }^{1}$, Mahesh Attimarad ${ }^{1}$, Sree Harsha $^{1}$ \\ ${ }^{1}$ Department of Pharmaceutical Sciences, College of Clinical Pharmacy, King Faisal University, Al-Ahsa, Kingdom of Saudi \\ Arabia, ${ }^{2}$ College of Pharmacy, Gulf Medical University, Ajman, United Arab Emirates
}

\begin{abstract}
Assessing the bioavailability of drug molecules at the site of action provides better insight into the efficiency of a dosage form. However, determining drug concentration in the skin layers following topical application of dermatological formulations is a great challenge. The protocols followed in oral formulations could not be applied for topical dosage forms. The regulatory agencies are considering several possible approaches such as tape stripping, microdialysis etc. On the other hand, the skin bioavailability assessment of xenobiotics is equally important for topical formulations in order to evaluate the toxicity. It is always possible that drug molecules applied on the skin surface may transport thorough the skin and reaches systemic circulation. Thus the real time measurement of molecules in the skin layer has become obligatory. In the last two decades, quite a few investigations have been carried out to assess the skin bioavailability and toxicity of topical/dermatological products. This review provides current understanding on the basics of dermatokinetics, drug depot formation, skin metabolism and clearance of drug molecules from the skin layers following application of topical formulations.
\end{abstract}

Uniterms: Dermatological formulations/pharmacokinetics. Dermatological formulations/ toxicity. Dermatokinetics. Skin/metabolism. Microdialysis. Tape stripping.

A avaliação da biodisponibilidade de moléculas de fármacos no sítio de ação oferece melhor compreensão sobre a eficiência da forma de dosagem. Entretanto, a determinação da concentração de fármaco nas camadas da pele em seguida à aplicação tópica de formulações dermatológicas é um grande desafio. Os protocolos seguidos para as formulações orais não podem ser aplicados para as formulações tópicas. As agências regulatórias consideram várias abordagens possíveis, tape stripping, microdiálise etc. Por outro lado, a avaliação da biodisponibilidade de xenobióticos na pele é igualmente importante para as formulações tópicas para se avaliar a toxicidade. É sempre possível que as moléculas de fármaco aplicadas na superfície da pele sejam transportadas através da pele e alcancem a circulação sistêmica. Assim, a medida em tempo real de moléculas na camada da pele tem se tornado obrigatória. Nas últimas duas décadas, realizaram-se poucas pesquisas para avaliar a biodisponibilidade da pele e a toxicidade de produtos tópicos/dermatológicos. Esta revisão fornece a compreensão atual com base na dermatocinética, formação de fármaco de depósito, metabolismo da pele e o clearance das moléculas de fármaco das camadas da pele em seguida à aplicação de formulações tópicas.

Unitermos: Formulações dermatológicas/farmacocinética. Formulações dermatológicas/toxicidade. Dermatocinética Pele/metabolismo. Microdiálise. Tape stripping.

\section{INTRODUCTION}

Topical dermatological formulations are primarily intended to deliver therapeutically effective concentration of drug in skin layers, which are also the target site. Indeed, treatment of superficial skin diseases such as

\footnotetext{
*Correspondence: Anroop Nair. Department of Pharmaceutical Sciences, College of Clinical Pharmacy, King Faisal University, P.O. 400, Al-Ahsa-31982, Kingdom of Saudi Arabia. E-mail: anair@kfu.edu.sa
}

fungal infections could be accomplished with topical formulations. Many dermatological formulations are available and are specifically designed to exert local effect in the diseased skin, rather than diffusing into the deeper layers of skin. Primarily these formulations are aimed to deliver a therapeutically effective drug concentration in the target tissue, to exert a local effect, following topical application. However, the presence of several excipients which are potential to solubilise the outer skin layers allows the entry of drug moieties in the deeper skin layers 
and even into systemic circulation. Novel vesicular formulations such as micro-emulsions, liposomes, and nanoparticles have demonstrated the potential to enhance cutaneous drug delivery of both lipophilic and hydrophilic drugs (Riviere, Brooks, 2011). It is understood that the properties of both formulation and drug are equally important in deciding the disposition of drug in the skin layers. Hence, it is likely that the individual drug molecule and excipient could exhibit different permeability behaviour (Desai et al., 2010). In addition, the presence of enzymes in skin causes variation of the structure of molecules and alters topical bioavailability. Hence, the in vivo activity of dermatological formulation depends on bioavailability of drug within the skin at the site of action (Bronaugh et al., 1994). In this context, researchers in the last few decades have given much emphasis on the assessment of skin kinetics of topical formulation. Following application of a topical drug formulation to the skin surface, it is likely that few processes occurs in a sequence such as release of drug from the dosage form, permeation of the drug into the skin barrier and exhibits the therapeutic responses such as onset of action, duration and magnitude of action.

The traditional methods for assessing the kinetics in blood, plasma or urine may not be viable as most of the topically applied molecules may not produce measurable concentrations in extra cutaneous biological fluids. It should also be remember that in topical therapy the drug concentration in the skin can significantly exceed free concentrations in plasma as the topical formulations deliver the drug directly to or near the intended site of action. Hence, determining drug absorption and elimination from the stratum corneum (SC) could be more promising. Thus, an ideal method to assess the skin kinetics would be a technique which allows non-invasive determination of rate and extent of drug within the skin. On the other hand, assessment of the rate and extent to which an active molecule attains its site of action in the target area (skin layers) is not considered as an easy task, due to the non availability of a simple and precise method for sampling the drug molecules from this region.

Bioavailability assessment of topical formulations remains a great challenge. Regulatory agencies like US Food and Drug Administration (FDA) have been exploring different strategies for the bioequivalence assessment of topical dermatological formulations. One of the methods suggested by FDA is the dermatopharmacokinetic (DPK) approach, wherein the drug concentration in the skin is determined continuously or intermittently for a period of time. Alternatively, microdialysis technique has been introduced to dermatological research as a valuable in vivo tool to assess the skin kinetics of topical formulations (Anderson et al., 1991; Kreilgaard, 2001). Further, several in vivo approaches have been also assessed to measure the topical bioavailability. This article provides a valuable insight into the basic considerations in the dermatokinetics of topical formulations.

\section{SKIN BARRIERS}

Skin is the largest organ of human body, which also act as a boundary between body and environment. It protects the body from chemical, physical, and microbial injury, loss of water, and other endogenous substances (Waugh, Grant, 2004). Skin covering an area of about $2 \mathrm{~m}^{2}$ in an average human adult. It receives approximately $1 / 3$ of all blood circulating through the body. Skin with a thickness of few millimetres separates the underlying blood circulation network from outside environment. Anatomically, the skin has three major tissue layers: the epidermis, dermis and hypodermis (Jain, 2001). Epidermis is the outermost layer of skin and comprises of stratified keratinised squamous epithelium varies in thickness in different regions of body (Aulton, 2007). Epidermis consists of different layers such as SC, stratum lucidum, stratum granulosum, stratum spinosum and stratum germinativum. The barrier function of skin is strongly attributed to the SC. It consisted of 15-20 layers of acutely flattened, metabolically inactive, polygonal cells having a dry weight density of $1.3-1.4 \mathrm{~g} / \mathrm{cm}^{3}$. Epidermis has no blood vessels or nerve endings, but its deeper layers are bathed in the interstitial fluid from dermis, which provides oxygen and nutrients and is drained away as lymph (Waugh, Grant, 2004). Dermis is tough and elastic, about 3-5 mm thick, essentially consists of $80 \%$ of protein and matrix of connective tissue woven from fibrous proteins (Jain, 2001; Aulton, 2007). Collagen fibres bind water and give the skin its tensile strength (Waugh, Grant, 2004). Branches from the arterial plexus supply blood to sweat glands, subcutaneous fat, hair follicles and dermis. Sweat glands are found all over the skin and most numbers in palms of soles of the feet, palms of the hand, axillae and groins. However, hair follicles are found all over the skin surface except soles of the feet, palms of the hand and red part of the skin (Aulton, 2007).

\section{DRUG ABSORPTION IN SKIN}

Absorption of drug or chemicals into the skin is influenced by several factors. These include molecular size, lipophilicity, $\mathrm{pH}$ of formulation, penetrant concentration, chemical enhancers, skin hydration, skin enzymes, 
temperature, formulation compositions etc and are discussed briefly.

Percutaneous absorption is inversely proportional to molecular weight, which particularly affects the diffusion coefficient. Molecules of size larger than 500 Daltons usually have more difficulty to penetrate through the SC (Bos, Meinradi, 2000). For optimal permeability lipid/ water partition coefficient is expected to be 1 or greater. Further, release of drug on to the skin surface is highly influenced by its partition coefficient and $\mathrm{pH}$ of vehicle. Application of formulation with a high or very low $\mathrm{pH}$ values can harm the skin. Hence a moderate $\mathrm{pH}$ values [typically above the isoelectric point ( $\mathrm{pI} 4$ ) of skin] could be more appropriate for topical delivery (Merino et al., 1999). However, degree of drug ionization at particular $\mathrm{pH}$ is of great importance, as unionized molecules predominantly diffuse through the lipophilic intercellular regions of the SC. On the other hand, the skin is negatively charged at physiological $\mathrm{pH}$ and therefore is cation-permselective (Marro et al., 2001). Furthermore, ionized drug molecules may also permeate through the intercellular regions of the SC, but in a slow and low mode. Moreover, ionized drug molecules forms pair with ion present in the skin, leads to neutral compounds which are competent of crossing the skin barrier (Govil, Tayle, 1998; Mishra, Jain, 2002; Mbah et al., 2011).

The concentration of drug in the formulation is equally important. A proportional increase in flux can be obtained by increasing the concentration of dissolved drug. At higher concentration above the solubility, the excess solid drug acts as a reservoir (often causes drug crystallization in patches) and maintain constant drug level for a prolonged time (Govil, Tayle, 1998; Mishra, Jain, 2002; Mbah et al., 2011). Further, the presence of any chemical permeation enhancers will augment the delivery of drugs into the skin layers. In addition, skin occlusion with impermeable plastic films or wraps prevents the water loss from the skin surface. This increases the level of hydration in the SC which in turn decreases the diffusional path length and protein network density, favouring the drug transport. The rate of occlusion decreases in following order: occlusive film $=$ transdermal patches $>$ lipophilic ointments $>$ w/o cream $>0 / w$ cream. For a large temperature variation $\left(10-37^{\circ} \mathrm{C}\right)$, the penetration rate of material through skin change $\sim 10$ folds, since diffusion coefficient decreases as temperature falls (Jetzer et al., 1988). Occlusive vehicles are likely to increase the skin temperature by $2-3^{\circ} \mathrm{C}$ resulting in increased molecular motion and permeability (Hotchkiss et al., 1992). Moreover, skin metabolizes chemical carcinogens, steroid hormones and certain topical drugs. Thus the therapeutic efficacy of topically applied compounds particularly prodrugs and carcinogenic responses in the skin may be determined by such metabolism (Aulton, 2007). Last but not least, the formulation compositions including the polymer are likely to influence both the drug release rate and the SC permeability (Kandavilli et al., 2002).

\section{Assessment of dermatokinetics}

Assessment of the skin kinetics of topical formulations is likely to provide the drug bioavailability of the applied formulation, which in turn results in the effective treatment of dermatological diseases. However, the definition of bioavailability for systemically acting drugs could not be extended to topical drugs. No correlation exists between the availability of drug in the skin and with the resulting blood levels. Hence the evaluation of topical bioavailability must involve the quantification of drug in target tissue itself. Indeed, most of the topical formulations are intended to act on the upper skin layers, rather than diffusing into and through the epidermis. For instance, the treatment of fungal infection of skin (wherein the fungi reside in the SC) and a direct measurement of drug at the site of action (SC) is likely to provide better insight in to the pharmacokinetics. However, in some instances, the target site for topical formulation may not be the SC although it will pass through this barrier, except when the $\mathrm{SC}$ is compromised (damaged/diseased condition). Hence the assessment of drug concentration in the SC should be generally applicable to all topical dermatological drug formulations including antifungal, antiviral, antiacne, antibiotic and corticosteroids.

The skin kinetics study is comparable to a typical blood, plasma, urine pharmacokinetic study. However, it must be borne in mind that the pharmacokinetic parameters in skin are not only dependent on the absorption (in the case of oral administration) but also depends on the time at which drug administration is stopped by removal of any remaining formulation on the skin surface. Further, the percutaneous absorption is a low and slow process and always there is possibility that the applied formulation will be removed before the absorption phase is completed. In general, the evaluation of DPK involves the assessment of the drug concentration in the outer most layers of the skin (SC) with respect to time and provides information on drug absorption, steady state and drug elimination based on a SC concentration-time curve (Guidance for Industry, 1998). Moreover, one of the in vitro- in vivo correlations for topical preparations can be obtained by measuring the drug release from formulation and in vivo measurement of drug concentration in the SC or DPK (Shah, 2005). 
Parameters such as maximum quantity of active drug molecules in the $\mathrm{SC}\left(\mathrm{C}_{\max }\right)$, time to reach maximum level $\left(\mathrm{T}_{\max }\right)$, and area under the curve of drug level in the SC versus time (AUC) are proposed as metrics for assessing bioequivalence of topical drugs (Shah, 1998). Following the topical application, drug levels in the SC is assessed as a function of time of post application and post removal of the formulation, to generate $\mathrm{SC}$ concentration versus time profile. The DPK method assumes that: (a) $\mathrm{SC}$ is the rate-limiting barrier to percutaneous absorption, (b) drug concentration in the SC is directly related to drug's diffusion into the viable dermis and (c) SC drug concentrations are more relevant for estimating local, dermatological efficacy than plasma concentrations (Nicoli et al., 2009). It has also been possible to deduce drug's partitioning and diffusion parameters which characterize the absorption process and which can subsequently be used to predict an entire absorption profile from a single short contact duration experiment (Shah, 1998).

\section{APPROACHES IN DERMATOKINETCIS STUDIES}

Frequent measurement of drug levels in the skin is essential to provide a good estimate of the drug amount in the skin as a function of time and to derive dermatokinetic parameters $\left(\mathrm{C}_{\max }, \mathrm{T}_{\max }\right.$ and $\left.\mathrm{AUC}\right)$ of a definite value. Hence the FDA draft guidance for DPK specifies that drug levels should be assessed at least eight different sites: at four of the sites levels are measured during uptake (e.g. 0.25, 0.5, 1 , and $3 \mathrm{~h}$ post-application), then, after cleaning the drug from the remaining sites, levels are assessed during clearance (e.g. $4,6,8$, and 24 h post application) (Guidance for Industry, 1998). However, it is likely that the amount of drug in samples measured after longer clearance times will be less than the limit of quantification or the limit of detection, which eventually leads to the incomplete or erratic data. Further it is also recommended to collect all the skin samples on a single day, in order to avoid inter day variation, which is of much concern due to the limited skin availability in a given subject. Moreover, the success of the skin kinetic study is equally dependent on the development of sensitive analytical methods to quantify the amount of drug. Certain invasive techniques such as indirect radiochemical methods, surface scrapping, sampling of hairs, suction blister sampling and biopsies, which are too non-specific or too traumatic, are not preferred for routine use in human and have not been discussed in this article. However, few feasible methods for the pharmacokinetic assessment of topically formulations such as tape stripping, microdialysis and vasoconstrictor assay are discussed below.

\section{Tape stripping technique}

Tape stripping is applied in various areas of cutaneous biology such as determination of the barrier function, inspect dermato-pathologies, examine gene expression, check $\mathrm{pH}$ profiles, inspect animal skin as a surrogate for human skin (Herkenne et al., 2008). Moreover, it presents an alternative for local bioavailability or bioequivalence assessment of topically applied drugs whose target is the underlying viable tissues (Lademann et al., 2009). This technique in its standardized form is well suited to determine the DPK of topical formulations, where the drug concentration is determined in the SC layers, which are progressively removed by tape stripping. This method is a simple, efficient, quick and relatively non-invasive approach to assess the quality and efficacy of drugs, excipients, cosmetics in the skin following the topical dermatological application (Escobar-Chávez et al., 2008). Indeed, the drug or excipients level in the skin can be determined either in the removed tape strips, or directly in the tape stripped skin. Typically, after topical application and penetration of formulations, the cell layers of SC are collected by the successive application and removal of adhesive tape (Figure 1). Then the drug concentration on each tape is determined individually, penetration profiles may be derived, as a function of depth within the SC (Russell, Guy, 2009). The data thus obtained could be used for comparison of the penetration of different formulations to assess the bioequivalence. The FDA draft guidance indicates the assessment of both drug uptake into and drug elimination from the SC by tape stripping technique. In addition, the method can be employed both in vivo and in vitro, and in humans and animals such as pigs, rats, guinea pigs and mice (Lademann et al., 2009).

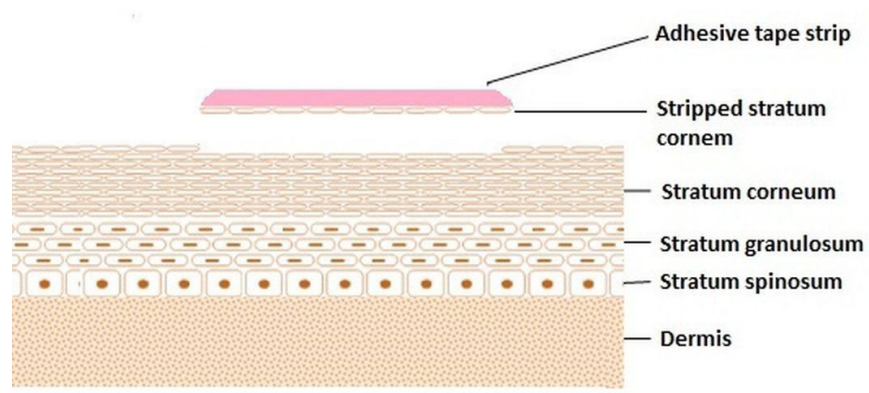

FIGURE 1 - Adhesive tape stripping of stratum corneum.

Several precautions need to be taken while carrying out the tape stripping (Boix-Montanes, 2011; Lademann et al., 2009). The first one could be the site of application. In general, the site of application must be free of both terminal and vellus hairs and uneven areas, e.g., caused 
by scars and underlying muscles. However, the hairy sites can be made useful after carefully removing the hair using scissors or special cutters but avoid shaving. Secondly, the choice of adhesive tape and its application for stripping the SC need to be optimized. One can use an adhesive tape directly or cutting it into definite size which possess uniform composition and distribution of the adhesive layer on the tape strip. However, attention should be made during application of adhesive tape strip to ensure complete adherence of tape on the marked skin area and avoid folding of tape. Further, application pressure should be constant in order to obtain a uniform removal of SC and to obtain a reproducible data. This can be achieved by using a constant weight or spatula or a roller, although the roller is preferred. In general, adhesive films are placed on the skin and applied a gentle force using a roller to stretch the skin surface and assure good contact (Nicoli et al., 2009). This in turn will avoid the influence of furrows and wrinkles under the tape stripping. Thirdly, velocity of stripping the tape; a constant velocity would be preferred which ensures removal of uniform amount of SC. Moreover, it must be kept in mind that the successive application and removal should be carried out from the same treated skin area. In addition, there are several factors which could eventually alter the quantity of SC removed in each adhesive tape strips. These include size of the corneocytes, number of cell layers, thickness of SC, age and composition and amount of lipids (depending on the anatomical site) (Lademann et al., 2009).

Several methods have been proposed to quantify the amount of SC removed by individual tape stripping. These include weighing, spectroscopic and microscopic measurements (Lademann et al., 2009). In the case of weighing method, weighing tapes before and after stripping has been used to estimate the mass of SC removed per tape. The mass is further converted to SC thickness using the area and SC density. The main limitation of this method is the process remains time consuming and laborious. However, the spectroscopic method will measure the amount of proteins in the corneocytes (component of SC) which has absorption at $278 \mathrm{~nm}$, and can be estimated using a spectrophotometer. On the other hand, optical microscope could be used to take the images of the corneocytes adhered to a tape strip and relative covering density is determined. The estimation of transepidermal water loss (TEWL) before the first tape strip and after a set number of tape strips to determine the exact number of tapes required for the complete removal of SC. A point wherein the TEWL attains $\sim 8$ times higher than the baseline value is an indicator that the SC is completely tape stripped (Shah, 2001).
The amount of drug in the tape strips can be estimated by extracting the amount of absorbed drug. One can correlate this drug level with those attained in the underlying viable components of the skin (Incecayir, 2011). In general, the first tape strip is discarded as it represents the drug on the skin surface (unabsorbed). However, the amount of SC removed by the first tape is highly influenced by the presence of furrows, formulation composition and the duration of study (Sheth et al., 1987).

The draft guidance by US Department of Health and Human Services in 1998 has proposed the determination of the drug level in the SC using tape stripping as a DPK approach to assess the bioequivalence (N'Dri-Stempfer $e t$ al., 2008). As mentioned before, the protocol specifies that each formulation should be applied to at least eight sites, divided equally for studying the kinetics (at four different times post-removal) of drug uptake and clearance. Each treatment is further tape stripped for 12 times, while the first two are discarded and the remaining is combined and quantified. It is also recommended that the performance of a topical formulation should be quantified in a similar manner which reflects the bioequivalence tests for oral drug bioavailability in which blood levels are measured (Guidance for Industry, 1998). The amount of drug determined in the tape strip samples should be represented as AUC, $\mathrm{C}_{\text {max }}$ and $\mathrm{T}_{\text {max }}$ (Figure 2), and a comparable data of two topical products would be considered bioequivalent. However, in 2002, the FDA partially withdrawn the DPK guidance due to doubts regarding the reproducibility of method and concern regarding the quantification of actives in the SC.

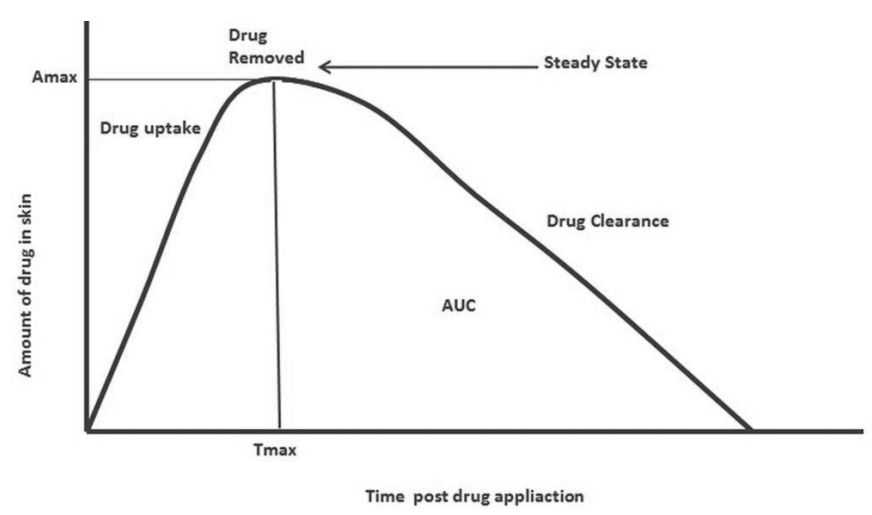

FIGURE 2 - Schematic diagram illustrating the DPK drug analysis in the stratum corneum by tape stripping methodology recommended in FDA guidance 1998.

\section{Microdialysis}

Microdialysis, a minimally invasive technique, 
has been introduced to dermatological research as a valuable in vivo tool for the assessment of bioavailability and bioequivalence of topical formulations (Anderson et al., 1991; Kreilgaard, 2001). This technique has been successfully applied to assess cutaneous drug delivery of numerous endogenous and exogenous compounds in the extracellular spaces of tissues and for assessing pharmacokinetic and pharmacodynamic response (Shah, 2001). Indeed this method is capable of measuring free drug concentrations at the site of drug action over time and thereby enables the assessment of local pharmacokinetic profile of topical drug penetration from each sampling site (Groth, 1996; Kreilgaard, 2001; Herkenne et al., 2008). Currently, this method has been recognized by the industries and regulatory authorities for bioavailability and bioequivalence determination of topical dermatologic products. Microdialysis is also combined with a wide variety of non invasive methods developed to observe barrier function and functional status of the skin (Schnetz, Fartasch, 2001).

A microdialysis probe consists of a small, semipermeable hollow fiber membrane $(\sim 0.4 \mathrm{~mm}$ diameter) that is connected to inlet and outlet tubing. The probes are of linear or concentric. Depending on the probe design, the fibre has one end connected to an afferent impermeable tube, which leads to a micropump, and the other end to an efferent sampling tube. During microdialysis, the probe is implanted in the dermis of the skin via a guide cannula, parallel to the skin surface, with or without local anesthesia at the site of entry. The microdialysis fibre is then constantly perfused with a sterile physiological solution (perfusate) at flow rates of approximately 0.1 to $5 \mu \mathrm{L} / \mathrm{min}$ through a microdialysis pump. In the dermis, probe functions as an artificial vessel, while the perfusate equilibrates extracellular fluid of surrounding tissue, and exchange substances smaller than the cut-off value of membrane from probe to tissue and vice versa (Ault et al., 1994). The mechanism for transport of solutes across the membrane is by passive diffusion depending on their concentration gradient. Hence, compounds can be separated or can be added to extracellular space by diffusion through dialysis membrane (Shah, 2001). The solution leaving the probe (dialysate) is collected at certain time intervals for analysis. Samples obtained are protein free and easily analysed without any further analytical purification. However, sampling of very lipophilic and highly protein bound drugs can produce problems due to their low recoveries with this technique. Further, relatively large differences in individual drug levels were observed in between individuals and between microdialysis probes. The recovery of substances is highly influenced by drug clearance from tissues surrounding microdialysis membrane, diffusivity of substance, capillary blood flow around the probe and partition coefficient between perfusates and tissues. These factors are likely to alter during an experiment and between application sites (Kreilgaard, 2001; Wu et al., 2009).

Important parameter for the efficacy of microdialysis is the relative recovery of probe, which has to be determined before performing microdialysis. Due to steady flow of perfusate through the probe, equilibrium between the concentration of dialysate and substance in extracellular fluid will be reached immediately. However, the steady state concentration of substance of interest $\left(C_{\text {dialysate }}\right)$ will not be same as in the extracellular fluid $\left(C_{\text {tissue }}\right)$ and the ratio represents relative recovery, which can be calculated as Relative Recovery $=\left\{\left(C_{\text {dialysate }}-C_{\text {perfusate }}\right) /\right.$ $\left.\left(C_{\text {tissue }}-C_{\text {perfusate }}\right)\right\}$ (Schnetz, Fartasch, 2001).

Microdialysis technique has been applied successfully in human volunteers to study the cutaneous release of histamine in response to different topical stimuli and the penetration of a number of organic solvents (ethanol and isopropranol). This could be utilized in measuring inflammatory mediators in dermis, study skin metabolism, determine the drug absorption or other agents in skin and as an alternative route of drug administration (Kreilgaard, 2002). Currently microdialysis exercised in the field of clinical research for the monitoring of secondary ischemia in neurointensive care or glucose monitoring for long term metabolic control in patients with diabetes mellitus. It can give very detailed chronological pharmacokinetic data and simultaneously several sampling sites can be considered in the same volunteer.

\section{Vasoconstrictor assay}

Human skin blanching assay also known as vasoconstrictor assay is a well established method used to assess the safety and efficacy of topical products during clinical studies. This method is restricted to the bioequivalence assessment of topical corticosteroid formulations (Larsson, 1991). Vasoconstrictor assay method follows the FDA guidance for topical dermatological glucocorticoids - in vivo bioequivalence (Kanfer, 2010). A hill top chamber $(\sim 1.2 \mathrm{~cm})$ is affixed to the skin surface with adhesive tape and specified volume of formulation or sample was applied in the chamber. Volar forearm regions are selected for drug application, at least $4 \mathrm{~cm}$ from the wrist and $4 \mathrm{~cm}$ from the antecubital fossa. Formulation is applied for a fixed duration and the chambers are removed and excess formulation is cleaned off, then skin blanching response is measured for 
a prescribed period of time (Guidance for Industry, 1995). The visual assessment is based on the application of an intensity scale 0-4 where zero indicates no blanching and numbers 1-4 assigned to increase in degree of blanching observed. The blanching response can be assessed by one or more observers used are taken into consideration for data processing. The total possible score expressed in percentage and is determined as (Kanfer, 2010);

$$
\text { Total possible score }=5 \times 4 \times S x V
$$

Where $\mathrm{V}$ is the number of subjects, $\mathrm{S}$ is the number of sites/product/arm, 4 signify the number of independent assessors and 5 represents the maximum score/site.

\section{Confocal laser scanning microscopy}

Confocal laser scanning microscopy is another important tool for the assessment of DPK parameters. The confocal images are possible for fluorescent drugs or probes and do not required to prepare the skin to make optical sections. This tool focuses a beam to a given depth within the tissue and measures the concentration of penetrant or drug molecule at the level of focus. Thus, this tool allows an investigator to generate a concentration profile following topical application of drug product (Grasso, Lansdown, 1972; Mayee, Rawat, 2010). The confocal images can be obtained in the plane parallel to sample surface or in the plane perpendicular (Wu et al., 2009). This method has been widely used in assessing drug penetration or distribution in the skin layers following topical application of microparticles, nanoparticles and vesicular systems such as liposomes, niosomes etc (Desai et al., 2013; Khurana et al., 2013; Verma et al., 2013; Wang et al., 2013).

\section{SKIN DRUG CLEARANCE}

The majority of dermatokinetic studies have focused on the absorption phase of DPK. However, the fate of the molecule after the absorption has not studied much, although is equally important in assessing the bioavailability of the topical formulations. It is likely that the drugs with distinct characters are likely to transport into the dermis and therein to the systemic circulation by entering lymphatic or blood vessels in the dermis (Murthy et al., 2010). Following skin permeation, the key process involved is clearance (Wiedersberg et al., 2009). The disposition of topically applied drug could be influenced by physicochemical properties and the manner in which the active species is presented to the skin; that is, the formulation.
The pharmacological effects of topical drugs or substances are directly dependant on microvascular parameters such as blood flow rate. The microenvironment inside the skin is a vibrant part of the body which alters constantly (Krestos, Kasting, 2005). The skin possesses a rich vascular network system which regulates and deals various activities in the skin (Krestos et al., 2004). Cutaneous microvasculature is enclosed in the papillary dermis (1-2 mm below the epidermal surface) and consists of two horizontal plexus (Haake, Holbrook, 1999; Cevc, Vierl, 2007). The lower one is located near the dermalhypodermal junction that gives rise to arterioles and venules. The second plexus located approximately 1-2 mm below the skin surface represent the boundary between the papillary and reticular dermis (Braverman et al., 1990). Three types of capillaries are found in the human bodycontinuous, fenestrated and discontinuous. Continuous capillaries are located in the skin and skeletal muscle, and are least permeable. The dermal capillary may be assumed as a bent, capital lambda shaped cylinder with its ventral part being broader internally and externally. The capillaries are most important in relation to the clearance because it is the first permeable parts of circulation encountered by a topically applied permeant (Braverman, 1997). Usually, there is one capillary per papilla and their surface density is approximately 50 or $60-70$ capillaries per $\mathrm{mm}^{2}$ of the skin surface (Wiedersberg, 2009).

Lymphatic clearance route has extremely high permeability which becomes important for macromolecules which are not able to cross the microvascular barrier due to their size. The lymphatic system has the function to take away debris of daily wear and tear in a tissue. In the human skin, lymphatics first appear at the subpapillary dermis (Wiedersberg, 2009). Initial lymphatic vessels are cylindrical microtubules approximately $50 \mu \mathrm{m}$ in diameter and are consists of weakened endothelial cells (Krestos et al., 2007). On the average, lymphatic channels have the number density of 0.3-1.5 $\mu \mathrm{m}^{2}$ (Wiedersberg, 2009). Large molecules such as proteins, large sugars are cleared entirely by lymph vessels when injected intradermally. The removal of these molecules gives an evidence of lymphatic utility of the skin (Spiegel et al., 1992). The transport of drug molecules is primarily by passive transport and pressure gradients across the blood tissue barrier. Several routes have been classified in the capillary wall structure as pathways available for exchange. Depending on the solutes size, nature and lipophilicity, they may prefer one or more of these pathways (Leu, 2001). Interendothelial cell junctions are the preferred pathway for the transport of hydrophilic solutes and also important for the small lipophilic solutes. They resemble the pores or slits filled 
with extracellular phase. Secondly, the endothelial cells allows the transport of lipophilic solutes, water etc (Michel, Curry, 1999). Dermal/ cutaneous clearance is highly related to physiology of the blood vessels and physicochemical properties of drug moieties. Parameters such as the thickness of blood vessel, area, distance between blood vessels and blood flow rate likely to alter the drug clearance.

\section{SKIN METABOLISM}

Skin contains all the major enzymes which are found in the liver and other tissues and are capable of catalysing a number of metabolic reactions. Metabolism of the topically applied compounds result in altered pharmacological and toxicological effects (Reed, Rubin, 2010). However, the activity of enzymes in skin has found to be less as compared to liver. Hence, the skin can act as a gateway for the entry of drug molecules into the body (Bronaugh, Maibach, 2002). There are number of chemical groups which are particularly susceptible to skin metabolism such as alcohols, acids, primary amines, esters etc. The viable dermis comprises of different drug metabolising enzyme include epoxide hydrolase, CYPs, transferases (N-acetyl transferases) glucuronyl transferases and sulfatases. Further, the metabolism of retinoic acid by a specific CYP isoform, CYP26A1 and the human keratinocytes contains transporter proteins which influence influx or efflux of some xenobiotics were reported (Bronaugh, Maibach, 2002). There are reports indicating the conjugation and oxidation/reduction of alcohols and acids by the skin enzymes. The drug molecules or chemical substances may exhibit greater or lesser biological activity that undergoes significant skin metabolism than predicted simply from skin penetration studies. The in vivo measurement of skin metabolism is difficult task because biological specimens may also contain metabolites from other tissues (Bronaugh et al., 1994). However, the skin metabolism can be evaluated by conducting in vitro permeation studies using viable skin or the metabolites can be measured in skin homogenate or in the receptor fluid (Bronaugh, 1995).

\section{DRUG DEPOT IN SKIN}

The formation of drug depot in the epidermal region of the skin following topical application has been reported in several scientific publications. In general, drug reservoir in the skin layers is likely to release over an extended period of time (Zhai, Maibach, 2004; Nair et al., 2011; Nair et al., 2012). Recently, the application of iontophoresis to create depot of acyclovir was reported which would be beneficial for the effective treatment of viral infections by providing sustained release of drug over an extended period (Anderson et al., 2003). Several investigations has reported the prospective of vesicular carrier systems to facilitate localization of drug at the application site by forming depot and reduce the frequency of application, decreases the dose and systemic side effects when compared to conventional topical therapies (Siddoju et al., 2011). Silver nanoparticles, quantum dots, functionalized fullerene etc have been used to investigate and substantiate the possible drug depot following the topical application (Murthy et al., 2011). Numerous reports have shown localization of nano systems at the SC layer and follicular regions (Lademann et al., 1997; Schulz et al., 2002; Lademann et al., 2007; Zvyagin et al., 2008). Quantum dots of different sizes have been used to study the penetrability of nanoparticles across the layers of skin. Vogt et al have showed that particles of $40 \mathrm{~nm}$ size have penetrated through the depth of $225 \mu \mathrm{m}$ or in the region of epidermis or papillary dermis (Vogt et al., 2006). Kohli and Alpar (2004) have shown that the penetrability of nanoparticles across the skin depends not only on the size but also on the charge present on the surface of the particles. In general, most of the studies have demonstrated the penetrability of nanoparticles in the size range of $<40 \mathrm{~nm}$ regardless of the surface charge across the SC via follicular as well as intercellular pathways. It is likely that the particles in this size range would be able to penetrate better if the intactness of the upper most layer, SC is compromised. In one attempt, titanium dioxide particle were exposed for 2-6 weeks in the epidermis and dermis of patients to determine amount of titanium in skin layers. The data indicate that there was no drug depot in the skin layers, although the exact reason is unidentified. On the other hand, lipid microparticles with $>1 \mu \mathrm{m}$ are able to retain on the skin surface or localized on the hair follicles surfaces and form a film layer on the skin surface which can be helpful in sunscreen formulations for the protection against UV radiation (Devi et al., 2011). The residence time in different skin layers can be determined by the tape stripping and skin extraction studies at various time intervals following drug application. In addition, topical drug deposition can be assessed quantitatively by tape stripping method and could be extended in determining the follicular deposition when it is used in combination with visualization by microscopic methods (Reed, Rubin, 2010).

\section{CONCLUSION}

Assessment of dermatokinetics of topical dermatological formulations is utmost important 
in assessing the safety and efficacy of the products. Numerous approaches are reported and being used to determine the real time measurement of molecules in the skin layers. Regulatory agencies like U.S. FDA are still exploring different techniques to characterize drug's dermatopharmacokinetics. Parameters such as maximum quantity of drug active molecule in the $\mathrm{SC}\left(\mathrm{C}_{\max }\right)$, time to reach maximum level $\left(\mathrm{T}_{\max }\right)$, and area under the curve (AUC) are widely assessed in dermatokinetics studies. Different methods are reported for assessing pharmacokinetic profile of topically applied drug molecules which includes tape stripping, microdialysis, vasoconstrictor assay, confocal laser scanning etc. Certain dermatological product applied on the skin surface is likely to permeate into the deeper tissue layers and reach systemic circulation. Further, most of the molecules enters into the dermis are quickly cleared by the microvascular system, although few molecules retain in the skin and produce depot effect.

\section{REFERENCES}

ANDERSON, C.R.; MORRIS, R.L.; BOEH, S.D.; PANUS, P.C; SEMBROWICH, W.L. Effects of iontophoresis current magnitude and duration on dexamethasone deposition and localized drug retention. Phys. Ther., v.83, p.161-170, 2003.

ANDERSON, C; ANDERSSON, T; MOLANDER, M. Ethanol absorption across human skin measured by microdialysis technique. Acta Derm. Venereol., v.71, p.389-393, 1991.

AULT, J.M; RILEY, C.M; MELTZER, N.M; LUNTE, C.E. Dermal microdialysis sampling in vivo. Pharm. Res., v.11, p.1631-1639, 1994.

AULTON, M.E. The design and manufacture of medicines. 3.ed. Edinburgh, New York: Churchill Livingstone Elsevier, 2007. p.568-578.

BOIX-MONTANES, A. Relevance of equivalence assessment of topical products based on the dermatopharmacokinetics approach. Eur. J. Pharm. Sci., v.42, p.173-179, 2011.

BOS, J.D.; MEINRADI, M.M. The 500 dalton rule for the skin penetration of chemical compounds and drugs. Exp. Dermatol., v.9, p.165-169, 2000.

BRAVERMAN, I.M. The cutaneous microcirculation: ultrastructure and microanatomical organization. Microcirculation, v.4, p.329-340, 1997.
BRAVERMAN, I.M; KEH, A.; GOLDMINZ, D. Correlation of laser doppler wave patterns with underlying microvascular anatomy. J. Invest. Dermatol., v.95, p.283-286, 1990.

BRONAUGH, R.L. Methods for in vitro skin metabolism studies. Toxicol. Mech. Methods, v.5, p.275-281, 1995.

BRONAUGH, R.L.; COLLIER, S.W.; MACPHERSON, S.E.; KRAELING, M.E. Influence of metabolism in skin on dosimetry after topical exposure. Environ. Health Perspect., v.102, p.71-74, 1994.

BRONAUGH, R.L.; MAIBACH, H.I. Topical absorption of dermatological products. New York: Mercel Dekker, 2002. p.102-103.

CEVC, G; VIERL, U. Spatial distribution of cutaneous microvasculature and local drug clearance after drug application on the skin. J. Controlled Release, v.118, p.1826, 2007.

DESAI, P.R; SHAH, P.P.; HAYDEN, P.; SINGH, M. Investigation of follicular and non-follicular pathways for polyarginine and oleic acid-modified nanoparticles. Pharm. Res., v.30, p.1037-1049, 2013.

DESAI, P.; PATLOLLA, R.R.; SINGH, M. Interaction of nanoparticles and cell-penetrating peptides with skin for transdermal drug delivery. Mol. Membr. Biol., v.27, p.247259, 2010.

DEVI, M.; KUMAR, M.S.; MAHADEVAN, N. AmphotericinB loaded vesicular systems for the treatment of topical fungal infection. Int. J. Recent Adv. Pharm. Res., v.4, p.3746, 2011.

ESCOBAR-CHÁVEZ, J.J.; MERINO-SANJUÁN, V.; LÓPEZ-CERVANTES, M.; URBAN-MORLAN, Z.; PIÑÓN-SEGUNDO, E.; QUINTANAR-GUERRERO, D.; GANEM-QUINTANAR, A. The tape-stripping technique as a method for drug quantification in skin. J. Pharm. Pharm. Sci., v.11, p.104-130, 2008.

GOVIL, S.K.; TYLE, P. Drug delivery: fundamentals and application. New York: Marrcel Dekker, 1998. p.385-406.

GRASSO, P.; LANSDOWN, A.B.G. Methods of measuring, and factors affecting, percutaneous absorption. J. Soc. Cosmet. Chem., v.23, p.481-521, 1972. 
GROTH, L. Cutaneous microdialysis: methodology and validation. Acta Derm. Venereol., v.197, p.1-61, 1996.

GUIDANCE FOR INDUSTRY. Topical dermatologic corticosteroids: in vivo bioequivalence. U.S. Department of Health and Human Services. Rockville: Food and drug administration, 1995. p.1-36, 1995. (Draft Guidance).

HAAKE, A.R.; HOLBROOK, K. The structure and development of skin. In: FREEDBERG, I.M.; EISEN, A.Z.; WOLFF, K.; AUSTEN, K.F.; GOLDSMITH, L.A.; KATZ, S.I.; FITZPATRICK, T.B.H. (Eds.). Dermatology in general medicine. New York: MCGraw- Hill, 1999. p.70-114.

HERKENNE, C.; ALBERTI, I.; NAIK, A.; KALIA, Y.N.; MATHY, F.X.; PRÉAT, V.; GUY, R.H. In vivo methods for the assessment of topical drug bioavailability. Pharm. Res., v. 25, p.87-103, 2008.

HERKENNE, C.; ALBERTI, I.; NAIK, A.; KALIA, Y.N.; MATHY, F.X.; PRÉAT, V.; GUY, R.H. In vivo methods for the assessment of topical drug bioavailability. Pharm. Res., v. 25, p.87-103, 2008.

HOTCHKISS, S.A.; MILLER, J.M.; CALDWELL, J. Percutaneous absorption of benzyl acetate through rat skin in vitro. 2. Effect of vehicle and occlusion. Food Chem. Toxicol., v.30, p.145-153, 1992.

INCECAYIR, T.; AGABEYOGLU, I.; DERICI, U.; SINDEL, $\mathrm{S}$. Assessment of topical bioequivalence using dermal microdialysis and tape stripping methods. Pharm. Res., v.28, p.2165-2175, 2011.

JAIN, N.K. Controlled and novel drug delivery. New Delhi: CBS publishers \& distributors, 2001. p.101-105.

JETZER, W.E.; HOU, S.Y.E.; HUQ, A.S.; DURAISWAMY, N.; HO, N.H.; FLYNN, G.L. Temperature dependency of skin permeation of waterborne organic compounds. Pharm. Acta Helv., v.63, p.197-201, 1988.

KANDAVILLI, S.; NAIR, V.; PANCHAGNULA, R. Polymers in transdermal drug delivery systems. Pharm. Technol., v.26, p.62-80, 2002.

KANFER, I. Strategies for the bioequivalence assessment of topical dermatological dosage forms. J. Bioequiv. Bioavailab., v.2, p.102-110, 2010.
KHURANA, S.; JAIN, N.K.; BEDI, P.M. Nanoemulsion based gel for transdermal delivery of meloxicam: physicochemical, mechanistic investigation. Life Sci., v.92, p.383392, 2013.

KOHLI, A.K.; ALPAR, H.O. Potential use of nanoparticles for transcutaneous vaccine delivery: effect of particle size and charge. Int. J. Pharm., v.275, p.13-17, 2004.

KREILGAARD, M. Assessment of cutaneous drug delivery using microdialysis. Adv. Drug Deliv. Rev., v.54, p.S99-S121, 2002.

KREILGAARD, M. Dermal pharmacokinetic of microemulsion formulations determined by in vivo microdialysis. Pharm. Res., v.18, p.367-373, 2001.

KRESTOS, K.; KASTING, G.B.; NITSCHE, J.M. Distributed diffusion-clearance model for transient drug distribution within the skin. J. Pharm. Sci., v.93, p.2820-2835, 2004.

KRESTOS, K.; MILLER, M.A.; ZAMRORA-ESTRADA, G.; KASTING, G.B. Partitioning, diffusivity and clearance of skin permeants in mammalian dermis. Int. J. Pharm., v.346, p.64-79, 2007.

KRESTSOS, K.; KASTING, G.B. Dermal capillary clearance: physiology and modelling. Skin Pharmacol. Physiol., v.18, p.55-74, 2005.

LADEMANN, J.; RICHTER, H.; TEICHMANN, A.; OTBERG, N.; BLUME-PEYTAVI, U.; LUENGO, J.; WEISS, B.; SCHAEFER, U.F.; LEHR, C.M.; WEPF, R.; STERRY, R. Nanoparticles-an efficient carrier for drug delivery into the hair follicles. Eur. J. Pharm. Biopharm., v.66, p.159-164, 2007.

LADEMANN, J.; JACOBI, U.; SURBER, C.; WEIGMANN, H.J.; FLUHR, J.W. The tape stripping procedureevaluation of some critical parameters. Eur. J. Pharm. Biopharm., v.72, p.317-323, 2009.

LADEMANN, J.; WEIGMANN, H.; RICKMEYER, C.; BARTHELMES, H.; SCHAEFER, H.; MUELLER, G.; STERRY, W. Skin penetration of titanium dioxide microparticles in a sunscreen formulation into the horny layer and the follicular orifice. Skin Pharmacol. Appl. Skin Physiol., v.12, p.247-256, 1999.

LARSSON, C.I. The use of an internal standard for control of the recovery in microdialysis. Life Sci., v.49, p.L73-L78, 1991. 
LEU, A.J.; HUSMANN, M.J.; HELD, T.; FRISULLO, R.; HOFFMANN, U.; FRANZECK, U.K. Measurement of the lymphatic clearance of the human skin using a fluorescent tracer. J. Vasc. Res., v.38, p.423-431, 2001.

MARRO, D.; GUY, R.H.; DELGADO-CHARRO, M.B. Characterization of the iontophoretic permselectivity properties of human and pig skin. J. Controlled Release., v.70, p.213-217, 2001.

MAYEE, R.; RAWAT, S. Pharmacokinetic studies of topical formulations-a review. Int. J. Pharm. Clin. Res., v.2, p.98$100,2010$.

MBAH, C.J.; UZOR, P.F.; OMEJE, E.O. Perspectives on transdermal drug delivery. J. Chem. Pharm. Res., v.3, p.680-700, 2011.

MERINO, V.; OPEZ, A.; KALIA, Y.N.; GUY, R.H. Electrorepulsion versus electroosmosis: Effect of $\mathrm{pH}$ on the iontophoretic flux of 5-fluorouracil. Pharm. Res., v.16, p.758-761, 1999.

MICHEL, C.C.; CURRY, F.E. Microvascular permeability. Physiol. Rev., v.79, p.703-761, 1999.

MISRA, A.N.; JAIN, N.K. Controlled and novel drug delivery. 1.ed. New Delhi: CBS publishers and distributors, 2002. p.101-107.

MURTHY, S.N.; NAIR, A.B.; HAMMER, N.; VAKA, S.R.K.; WRIGHT, A.E. Dermatokinetics of nanoparticles ( $\sim 25 \mathrm{~nm})$. Int. J. Innovations Pharm. Res., v.1, p.37-43, 2010.

NAIR, A.B.; VYAS, H.; SHAH, J.; KUMAR, A. Effect of permeation enhancers on the iontophoretic transport of metoprolol tartrate and the drug retention in skin. Drug Deliv., v.18, p.19-25, 2011.

NAIR, A.B.; VAKA, S.R.K.; GUPTA, S.; REPKA, M.A.; MURTHY, S.N. In vitro and In vivo evaluation of a hydrogel based prototype transdermal patch system of alfuzosin hydrochloride. Pharm. Technol. Dev., v.17, p.158-163, 2012.

N'DRI-STEMPFER, B.; NAVIDI, W.C.; GUY, R.H.; BUNGE, A.L. Optimizing metrics for the assessment of bioequivalence between topical drug products. Pharm. Res., v.25, p.1621-1630, 2008.
NICOLI, S.; BUNGE, A.L.; DELGADO-CHARRO, M.B.; GUY, R.H. Dermatopharmacokinetics: factors influencing drug clearance from stratum corneum. Pharm. Res., v.26, p.865-871, 2009.

REED, R.K.; RUBIN, K. Transcapillary exchange: role and importance of the interstitial fluid pressure and the extracellular matrix. Cardiovasc. Res., v.87, p.211-217, 2010.

RIVIERE, J.E.; BROOKS, J.D. Predicting skin permeability from complex chemical mixtures: dependency of quantitative structure permeation relationships on biology of skin model used. Toxicol. Sci., v.119, p.224-232, 2011.

RUSSELL, L.M.; GUY, R.H. Measurement and prediction of the rate and extent of drug delivery into and through the skin. Expert Opin. Drug Deliv., v.6, p.355-369, 2009.

SCHNETZ, E.; FARTASCH, M. Microdialysis for the evaluation of penetration through the human skin barrier - a promising tool for future research? Eur. J. Pharm. Sci., v.12, p.165-174, 2001.

SCHULZ, J.; HOHENBERG, H.; PFLÜCKER, F.; GÄRTNER, E.; WILL, T; PFEIFFER, S.; WEPF, R.; WENDEL, V.; GERS-BARLAG, H.; WITTERN, K.P. Distribution of sunscreens on skin. Adv. Drug Deliv. Rev., v.54, p.157-163, 2002.

SHAH, P.P.; DESAI, P.R.; CHANNER, D.; SINGH, M. Enhanced skin permeation using polyarginine modified nanostructured lipid carriers. J. Controlled Release, v.161, p.735-745, 2012.

SHAH, V.P. IV-IVC for topically applied preparations--a critical evaluation. Eur. J. Pharm. Biopharm., v.60, p.309-314, 2005.

SHAH, V.P. Progress in methodologies for evaluating bioequivalence of topical formulations. Am. J. Clin. Dermatol., v.2, p.275-280, 2001.

SHAH, V.P. Topical dermatological drug product NDAs and ANDAs-in vivo bioavailability, bioequivalence, in vitro release and associated studies. Rockville: US Department of Health and Human Services, 1998. p.1-19. 
SHETH, N.V.; MCKEOUGH, M.B.; SPRUANCE, S.L. Measurement of the stratum corneum drug reservoir to predict the therapeutic efficacy of topical iododeoxyuridine for herpes simplex virus infection. J. Invest. Dermatol., v.89, p.598-602, 1987.

SIDDOJU, S.; SACHDEVA, V.; FRIDEN, P.M.; YU, Y.Y.; BANGA, A.K. Acyclovir skin depot characterization following in vivo iontophoretic delivery. Skin Res. Technol., v.17, p.234-44, 2011.

SINKO, P.J. Martin's physical pharmacy and pharmaceutical sciences: physical, chemical and biopharmaceutical principles in the pharmaceutical sciences. 6.ed. Philadelphia: Lippincott Williams \& Wilkins, 2006. p.304-305.

SPIEGEL, M.; VESTI, B.; SHORE, A.; FRANZECK, U.K.; BECKER, F.; BOLLINGER, A. Pressure of lymphatic capillaries in human skin. Am. J. Physiol., v.262, p.H1208-H1210, 1992.

GUIDANCE FOR INDUSTRY. Topical dermatological drug product NDAs and ANDAs-in vivo bioavailability, bioequivalence, in vitro release, and associated studies, Rockville: Food and Drug Administration, 1998. 19 p. (Draft Guidance).

VERMA, D.D.; VERMA, S.; BLUME, G.; FAHR, A. Liposomes increase skin penetration of entrapped and nonentrapped hydrophilic substances into human skin: a skin penetration and confocal laser scanning microscopy study. Eur. J. Pharm. Biopharm., v.55, p.271-277, 2003.

VOGT, A.; COMBADIERE, B.; HADAM, S.; STIELER, K.M.; LADEMANN, J.; SCHAEFER, H.; AUTRAN, B.; STERRY, W.; BLUME-PEYTAVI, U. $40 \mathrm{~nm}$, but not 750 or $1,500 \mathrm{~nm}$, nanoparticles enter epidermal cdla + cells after transcutaneous application on human skin. J. Invest. Dermatol., v.126, p.1316-1322, 2006.
WANG, Y; SU, W.; LI, Q.; LI, C.; WANG, H.; LI, Y.; CAO, Y.; CHANG, J.; ZHANG, L. Preparation and evaluation of lidocaine hydrochloride-loaded TAT-conjugated polymeric liposomes for transdermal delivery. Int. J. Pharm., v.441, p.748-756. 2013.

WAUGH, A.; GRANT, A. Ross and Wilson anatomy and physiology in health and illness. 9.ed. Edinburgh, New York: Churchill Livingstone Elsevier, 2004. p.361-364.

WIEDERSBERG, S.; NAIK, A.; LEOPOLD, C.S.; GUY, R.H. Pharmacodynamics and dermato- pharmacokinetics of betamethasone 17-valerate: assessment of topical bioavailability. Br. J. Dermatol., v.160, p.676-686, 2009.

WU, X.; PRICE, G.J.; GUY, R.H. Disposition of nanoparticles and an associated lipophilic permeant following topical application to the skin. Mol. Pharmacol., v.6, p.1441-1448, 2009.

ZHAI, H.; MAIBACH, H.I. The textbook of dermatotoxicology. 6.ed. London: CRC Press, 2004. p.623-625.

ZVYAGIN, A.V; ZHAO, X; GIERDEN, A; SANCHEZ, W; ROSS, J.A; ROBERTS, M.S. Imaging of zinc oxide nanoparticle penetration in human skin in vitro and in vivo. J. Biomed. Opt., v.13, p.64031, 2008.

Received for publication on $30^{\text {th }}$ May 2012 Accepted for publication on $20^{\text {th }}$ May 2013 